Studies in African Linguistics

Volume 27, Number 2, Fall 1998

\title{
THE MARKING OF GRAMMATICAL RELATIONS IN SWAHILI
}

\author{
Mayrene Bentley \\ Michigan State University
}

\begin{abstract}
This paper investigates the place of Swahili within a typological classification based on the morphological marking of grammatical relations as proposed by Nichols [1986]. Within Nichols' classification, Bantu languages are considered to be "split-marked" because the grammatical marking of a member of a clausal constituent is on the head while, in a phrase, the marking is on the dependent member. Although select clauses and phrases from Swahili support Nichols' claim, a closer examination of the data reveals an interesting variety of morphosyntactic marking in Swahili as well as in two other Bantu languages, Kikuyu and Chewa. Function words play a key role in marking genitive, instrumental, and locative relations in these languages. Function words also regularly occur as markers of object noun phrases with animate referents. Moreover, instrumental, locative, applicative, and some accusative relations in Swahili show considerable flexibility with respect to head- and non-head-marking.
\end{abstract}

\section{Introduction}

In Nichols' [1986] important typological study of the principal strategies for marking grammatical relations in the languages of the world, she has identified two tendencies: head-marking and dependent-marking. A given construction is considered head-marked if the syntactic dependence between the head and its argument is morphologically realized on the head. Likewise, a construction is considered dependent-marked if the syntactic dependence between the head and its dependent is morphologically realized on the dependent element. Although languages typically favor one strategy over another, both tendencies may occur independently in one language. Bantu languages, according to Nichols, incorporate both types of marking, that is, they are split-marked languages.

The goal of this paper is to reexamine the classification of Bantu languages as split-marked. Evidence suggests that the marking of grammatical relations in Swahili (an Eastern Bantu language) is not an unambiguous split between headmarked clauses and dependent-marked phrases. The marking of clausal and 
phrasal relations in Swahili is mixed with some relations having more than one means of marking. In addition to reexamining the place of Bantu languages within the two principal marking strategies, I will also address the nature of the dependent marker.

With respect to the nature of grammatical marking in Bantu, Nichols implies, through her examples from Tonga, that head and dependent-marking are affixal in Bantu. While head-marking is often affixal, dependent-marking is affixal in only limited cases. Furthermore, some pronominal forms in Bantu appear to be dependent-marked because they carry the gender of a corresponding noun; for example, possessive pronouns are bound stems and necessarily occur with a prefix. Hence, what appears to be dependent-marking may, in fact, be head-marking.

Finally, when Nichols [1986:64] classifies "familiar morphological categories and processes as either head-marked or dependent-marked", she provides no entry for inflected adpositions which govern cases. Instead, she lists under the rubric, dependent-marked, "uninflected adpositions which govern cases", and under head-marked, "inflected adpositions". The omission of the category inflected adpositions which govern cases is problematic if a comprehensive classification of the morphological processes in Bantu langauges is to be achieved. In addition, to what extent does a language qualify as split-marked if function words play an important role in marking grammatical relations in the language?

The organization of this paper is as follows: section 2 illustrates the morphosyntactic marking of two semantically equivalent clauses in which the presence of an object noun phrase (NP) that bears the semantic role of beneficiary or source may be marked in some instances by word order, by a free morpheme or phrasal expression, or by an affix on the head; section 3 argues that genitive phrases are not unambiguously dependent-marked in Bantu; section 4 illustrates examples of locative relations which are consistently marked by free morphemes in Swahili; section 5 concludes with data from Swahili illustrating complementary patterns (head-marked and non-head-marked) for instrumental and some locative relations at the clausal level; and section 6 summarizes the implications of the description put forth in this study.

\section{Head-marking versus dependent-marking}

In Bantu languages, the syntactic relation between a verb and a dependent noun such as the subject is marked on the tensed verb stem or head. The marking of arguments on a head within a clause qualifies the Bantu family as head-marked. In contrast to head-marked clauses, as Nichols [1986] points out, certain noun phrases in Bantu mark the relation between a noun and its modifier on the modifier or dependent. Because Bantu nouns mark their gender on a corresponding modifier, such as an adjective, phrases in Bantu are considered dependent- 
marked. While this split between head-marked clauses and dependent-marked phrases is appealing for its straightforward simplicity, the situation in Bantu is more complex than that suggested by Nichols. Nichols' split-marking classification was previously shown to be too constrained when describing the marking of object NPs functioning as goals in Swahili, Kikuyu, and Chewa [Bentley, in press]. An NP functioning as goal may be marked by an affix on the verb or by a free morpheme for a restricted set of verbs in these languages.

It is well known that in Bantu languages, the presence of a third argument is marked on the verb by an affix known as the applicative (APP). The applicative covers all the functions associated with the dative case, such as beneficiary, recipient, goal, source, and instrument. In addition to the applicative marker, a second verbal affix (object marker) indexes the features of the coreferential NP in the case of animate object NPs in Swahili. All pronominal expressions functioning as objects are also indexed on the head in Swahili. The presence of a single object-marking slot in Swahili favors the marking of animate objects in the case of double-object constructions [Bentley 1994, Vitale 1981:44]. Swahili neces-sarily selects the animate object NP. This is shown in (1) where an animate NP functioning as beneficiary is illustrated using a lexical NP in (1a), an interrogative in (1b), and a pronoun in (1c). ${ }^{1}$

(1) Swahili
a. Mama a-li-wa-pik-i-a
watoto chakula.
mama 3S-PST-3P-cook-APP-FV children food
'Mama cooked the children some food.'
b. Mama a-li-m-pik-i-a nani chakula?
mama 3S-PST-3S-cook-APP-FV who food
'For whom did Mama cook some food?'
c. Mama a-li-wa-pik-i-a (wao) chakula.
mama 3S-PST-3P-cook-APP-FV them food
'Mama cooked them some food.'

In addition to the head-marked clauses in (1), there exists a corresponding non-head-marked pattern in which the beneficiary NP occurs after the phrasal expression, kwa ajili ya. In (2c), the pronominal form or possessive, -ao, is a bound stem. It necessarily attaches to ya-.

${ }^{1}$ Unattributed examples are from my own data or from my informants: Alwiya Omar, Ahmed Shariff, Zamzam Mohammed Seif, Sanura Amour Azeez, Chege Githiora, Mungai Mutonya, Alice Nkungula, Lisungu Kamkando, and Wilson Ndovi. 
(2) Swahili

a. Mama a-li-pika chakula kwa ajili ya watoto. mama 3S-PST-cook food on behalf of children 'Mama cooked food on behalf of the children.'

b. Mama a-li-pika chakula kwa ajili ya nani? mama 3S-PST-cook food on behalf of who 'On behalf of whom did Mama cook food?'

c. Mama a-li-pika chakula kwa ajili yao. mama 3S-PST-cook food on behalf of.their 'Mama cooked food on behalf of them.'

Comparable constructions exist in Kikuyu. The examples in (3) illustrate the applicative construction, while those in (4) illustrate equivalent sentences with the corresponding phrasal expression, nĩ ũndũ wa.

Kikuyu

(3) a. Nda-rug-ĩ-ire ciana irio.

1S-cook-APP-PST children food

'I cooked the children food.'

b. Wa-rug-ĩ-ire ũ (i)rio?

2S-cook-APP-PST who food

'Who did you cook food for?'

c. (Cio) ni-nda-ci-rug-ĩ-ire (i)rio.

3P FOC-1S-3P-cook-APP-PST food

'I cooked them food.'

(4) a. Nda-rug-ire irio ñ̃ ũndũ wa ciana.

1S-cook-PST food because of children

'I cooked food because of the children.'

b. Wa-rug-ire irio nĩ ũndũ wa ũ?

2S-cook-PST food because of who

'Because of whom did you cook food?'

c. Nĩ-nda-rug-ire irio nĩ ũndũ wa cio.

FOC-1S-cook-PST food because of them

'I cooked food because of them.'

Although Swahili and Kikuyu have phrasal strategies to accomodate a nonhead-marked object NP functioning as beneficiary, Chewa has only the headmarked strategy as illustrated in example (5a). Example (5b) uses the expression 
$k w a$, which is not acceptable here. Its meaning in normal usage would be, 'The fool bought a gift from the girls.'

\section{(5) Chewa}

a. Chitsîru chi-na-gúl-ír-a atsíkána mphâtso.

7-fool 7-PST-buy-APP-FV 2-girls 9-gift

'The fool bought a gift for the girls.'

[Alsina \& Mchombo 1993:18]

b. *Chitsîru chi-na-gúl-a mphâtso kwa atsíkána 7-fool 7-PST-buy-FV 9-gift 2-girls

In addition to the beneficiary relation, ${ }^{2}$ Swahili has another clausal relation with the potential for both head and non-head-marking. In the head-marked examples in (6), the animate object NP functioning as source is cross-referenced on the verb. In these examples, the verb phrase, -omba samahani 'beg forgiveness', occurs without an applicative suffix. ${ }^{3}$

(6) Swahili

a. A-li-mw-omba mwalimu samahani.

3S-PST-3S-beg teacher forgiveness

'He asked the teacher for forgiveness.

b. A-li-mw-omba nani samahani?

3S-PST-3S-beg who forgiveness

'Whom did he ask for forgiveness?

c. A-li-mw-omba (yeye) samahani.

3S-PST-3S-beg (him) forgiveness

'He asked him for forgiveness.'

In the complementary non-head-marked patterns in (7), the animate object NP is not cross-referenced on the verb but occurs after the function word, $k w a$. ( $K w a$ is derived from the prefix $k u-$, a locative marker, and the relational stem -a to make $k w+a$.) In the case of the pronominal stem, -ake, the stem always attaches to the head, $k w a$.

(7) Swahili

a. A-li-omba samahani kwa mwalimu.

3S-PST-beg forgiveness from teacher

'He asked forgiveness from the teacher.'

2 See Bentley [in press] for the recipient/goal relation.

3 Related expressions in Swahili use this same pattern. For example: -omba kazi 'beg for work', and -omba ruhusa 'take leave'. 
b. A-li-omba samahani kwa nani?

3S-PST-beg forgiveness from who

'From whom did he ask forgiveness?'

c. A-li-omba samahani kwake.

3S-PST-beg forgiveness from.his

'He asked forgiveness from him.'

A comparable construction occurs in Kikuyu with the verb phrase, -hoya rutha 'beg permission'. Unlike Swahili, Kikuyu does not cross-reference the animate object NP. However, the animate object NP occurs before the inanimate NP in post-verbal word order. This is illustrated by the examples in (8).

(8) Kikuyu

a. Nĩ-a-ho-ire mwarimu rũtha.

FOC-3S-beg-PST teacher permission

'He asked the teacher for permission.'

b. A-ho-ire ũ rũtha?

3S-beg-PST who permission

'Whom did he ask for permission?'

c. Nĩ-a-mũ-ho-ire rũtha.

FOC-3S-3S-beg-PST permission

'He asked him for permission.'

Like Swahili, Kikuyu has an alternative means for marking the animate object. The object is marked by the free form, kũri, and follows the NP, rũtha, 'permission', illustrated by the examples in (9).

(9) Kikuyu

a. Nĩ-a-ho-ire rũtha kũrĩ mwarimu.

FOC-3S-beg-PST permission from teacher

'He asked permission from the teacher.'

b. A-ho-ire rũtha kũrĩ ũ?

3S-beg-PST permission from whom

'Whom did he ask for permission?'

c. Nĩ-a-ho-ire rũtha kũrĩ we.

FOC-3S-beg-PST permission from him

'He asked permission from him.' 
Chewa, unlike Swahili and Kikuyu, has only one possibility for marking the arguments of the verb phrase, -funsa chilolezo 'beg permission'. This strategy marks the animate object NP with the free form, kwa, as shown in (10).

\section{(10) Chewa}

a. Ndi-na-funsa chilolezo (kuchokela) kwa aphunzitsi. 1S-PST-ask permission from teacher 'I asked permission from the teacher.'

b. U-na-funsa chilolezo kwa ndani?

2S-PST-ask permission from who

'Whom did you ask permission from?'

c. Ndi-na-funsa chilolezo (kuchokela) kwa iye 1S-PST-ask permission from him 'I asked permission from him.'

The possibilites for marking beneficiary and source NPs in Swahili, Kikuyu, and Chewa are summarized below. 4

\section{Beneficiary}

Swahili $-V e r b-A P P-F V ~ N_{\text {[ben] }} \mathrm{N}_{\text {[pat] }} \quad-$ Verb-FV $\mathrm{N}_{\text {[pat] }} k w a$ ajili ya $\mathrm{N}_{[\text {ben] }}$

Kikuyu $\quad-$ Verb-APP-FV $\mathrm{N}_{\text {[ben] }} \mathrm{N}_{\text {[pat] }} \quad$-Verb-FV $\mathrm{N}_{\text {[pat] }}$ nĩ ũndũ wa $\mathrm{N}_{\text {[ben] }}$

Chewa -Verb-APP-FV $\mathrm{N}_{[\text {ben] }} \mathrm{N}_{\text {[pat] }}$

\section{Source}

Swahili -Verb-FV $\mathrm{N}_{\text {[source] }} \mathrm{N}_{\text {[pat] }}$

Kikuyu -Verb-FV $\mathrm{N}_{\text {[source] }} \mathrm{N}_{\text {[pat] }}$

Chewa
-Verb-FV $\mathrm{N}_{\text {[pat] }} k w a \mathrm{~N}_{\text {[source] }}$

-Verb-FV $\mathrm{N}_{\text {[pat] }} k \tilde{u} \tilde{r} \tilde{\mathrm{N}} \mathrm{N}_{\text {[source] }}$

-Verb-FV N[pat] $k w a \mathrm{~N}_{\text {[source] }}$

These data suggest that certain clausal relations in Bantu are not restricted to head-marking as proposed by Nichols. Certain dependency relations in Bantu clauses may be marked either on the head or by a free morpheme in Swahili and Kikuyu. In Chewa, the beneficary relation is head-marked and the source relation non-head-marked.

In this section, the examples of grammatical relations marked by free morphemes have been clausal. In the following two sections, I will show that two phrasal relations in Bantu, genitive and locative, use free morphemes to mark grammatical relations.

${ }^{4}$ AGR=agreement, APP=applicative, $\mathrm{FV}=$ final vowel, $\mathrm{N}=$ =noun, ben=benefactive, pat=patient. 


\section{Genitive relations}

Natural languages typically rely on a combination of strategies for encoding relations other than subject and object. These strategies often include prepositions and postpositions [Blake 1994:161]. In Swahili, a function word marks the relation genitive. This functional word is derived from the relational stem, -a, plus a noun class prefix..$^{5}$ The possessed noun head governs the class prefix on the relational stem, $-a$. This derived preposition, in turn, governs the possessor dependent noun. If the possessor is a pronominal, the genitive case is used and not the nominative. Since the genitive pronoun is a stem in Bantu, it necessarily attaches to its prepositional head. The resulting form is an inflected adposition which governs case, the case being the genitive. This is illustrated in (11a-c). Comparable constructions exist in Kikuyu (12) and in Chewa (13).

(11) Swahili 3-bag 3.ASC Ahmed
'Ahmed's bag'
a. m-fuko wa Ahmed
b. m-fuko wa nani
3-bag 3.ASC who
'whose bag'
c. m-fuko wake /*wa yeye
3-bag 3.ASC.his / 3.ASC 3S
'his bag'

(12) Kikuyu
child 1.ASC European
'child of a European'
a. mwana wa Mũthũngũ
b. mwana wa ũ
child 1.ASC who
'whose child'
c. mwana wake /*wa we child 1.ASC.his / 1.ASC 3S 'his child'

5 The stem -a has traditionally been labeled an associative marker. Hence, I use here the label ASC for glossing purposes. 
(13) Chewa
a. njingá yá mw-ána w-á-m-ng'óono
9.bicycle 9.ASC 1-child 1-ASC-1-small
'bicycle of a small child'
[Kanerva 1990:12]
b. njingá yá ndani
9.bicycle 9.ASC who
'whose bicycle'
c. njingá yáke /*yá iye
9.bicycle 9.ASC.his / 9.ASC 3S
'his bicycle'

From these examples, we see that the genitive marker appears as an affix only on the possessive pronominal stem and not on lexical and interrogative NPs in Swahili, Kikuyu, and Chewa. In contrast to these languages, Nichols shows that in Tonga, the genitive marker appears as an affix on the lexical NP. Because of its morphological dependence, Nichols claims that the genitive relation in Bantu is a dependent-marked relation. Nichols' example is repeated here in (14).

(14) Tonga [Carter 1963 quoted in Nichols 1986:72]

í-kú-bòkò í-kú-á-mú-kàìntù

DEF-15-arm DEF-15-ASC-1-woman

'the woman's arm'

According to Vicki Carstens [p.c.], when the dependent is a phrase as in example (14), then the noun head of the dependent phrase marks the dependent for gender. Hence, the dependent or possessor NP in example (14), mú-kàintù, bears the gender of the possessed noun head, í-kú-bòkò. However, because the dependent possessor argument is a phrase, í-kú-á-mú-kàintù, the dependent marking is carried by the dependent head, -a-. Thus, the genitive marker, kú-á-, functions simultaneously as a head and a dependent.

Further evidence for the claim that -a-functions as a head comes from Tswana. In Tswana the genitive marker, wa-, appears as an affix on the dependent lexical NP, motsomi, as shown in (15). Although written as an affix on the lexical NP in Tswana and, therefore, understood by Nichols to be a dependentmarked relation, the genitive marker is an inflected adposition which governs the genitive case in pronominals, as illustrated in (16). 


\title{
Tswana
}

(15) mo-sadi w-a-mo-tsomi

1S-woman 1S-ASC-1S-hunter

'the wife of the hunter'

[Cole 1955:166]

\author{
(16) n-tlo y-a-me /*ya nna \\ 5.house 5-ASC-my / 5.ASC1S \\ 'my house' \\ [Cole 1955:162]
}

Because lexical NPs and interrogatives are not marked for case in Tswana, Swahili, Kikuyu, or Chewa, the pronominal form provides evidence that the genitive marker is a head, although simultaneously marked as a dependent.

Further evidence that the genitive in Bantu is not a simple marker of dependency is seen in an example from Swahili. In response to the question $\mathrm{Ni}$ mtoto wa nani? 'Whose child is this?', example (17b) shows that a determiner/ demonstrative may occur between the genitive marker and the dependent lexical NP. The genitive marker never attaches to the demonstrative in Swahili (*wayule).

(17) Swahili

a. Ni m-toto wa nani?

is 1-child 1.ASC who

'Whose child is this?'

b. Ni m-toto wa yu-le mama hodari. is 1-child 1.ASC 1-the mother clever 'It's the child of the clever mother'

Although Swahili permits a determiner/demonstrative to appear between the genitive and its possessor NP, Kikuyu finds this order of elements acceptable only if a "comma intonation" occurs before the possessor NP [Mugane 1998]. The same holds true for Chewa, where a pause occurs after the demonstrative, uyo, as in (18).

(18) Chewa

a. Ndi mwana wa ndani?

is 1.child 1.ASC who

'Whose child is this?'

b. Ndi mwana wa uyo, mayi wo-kongola.

is 1.child 1.ASC that mother 1-beautiful

'It's the child of that one, the beautiful mother.' 
The data in this section highlight the ambiguity of Nichols' claim that genitive phrases are dependent-marked in Bantu. Although the dependent or possessor NP is marked by an inflected adposition, the marker itself functions as a head since it governs case. This is especially evident in the case of pronominals. As to morphological affixing, we have seen that the genitive marker necessarily attaches to the possessive stem in Swahili, Kikuyu, Chewa, and Tswana. Written tradition separates the genitive marker from lexical and interrogative NPs in Swahili, Kikuyu and Chewa. It remains for future research to determine a hierarchy of NP types-from pronouns to proper names-that captures the likelihood of an NP to affix the genitive marker. ${ }^{6}$

\section{Locative relations}

Like the genitive, certain locative relations in Bantu are marked by free morphemes. In Swahili, the derived form $k w a$ is used to show movement to or from a person [Adam 1993:168]. This is illustrated in example (19a) with the lexical NP, rafiki yangu. In (19b) kwa occurs before the interrogative nani 'who', and in (19c) it combines with a possessive pronominal stem to mean at someone's dwelling.

(19) Swahili
a. Ni-na-kwenda kwa rafiki yangu.
1S-PR-go to friend my
'I am going to my friend.'
[Adam 1993:169]
b. U-ta-kwenda kwa nani?
2S-FUT-go to who
'Whose house will you go to?'
c. Ni-ta-kwenda $k w$-ake /*kwa yeye.
1S-FUT-go to-ASC.his / to 3S
'I will go to his home.'

$K$ wa is invariable; it bears no dependency marker. It occurs as a free morpheme before lexical and interrogative NPs but as a prefix on the possessive stem in Swahili. In Kikuyu and Chewa, the forms $g$ wĩ/kwi and $k w a$, respectively, occur independently of the NPs which they mark. ${ }^{7}$ Unlike Swahili, Kikuyu

\footnotetext{
6 It is possible that the genitive marker in Bantu manifests characteristics similar to the function word of in English. Although of is clearly a free morpheme, it shows affixal properties in phrases such as "full astuff" and "chest adrawers".

7 According to Mugane [1997:22], gender in Kikuyu does not determine "the morphological shape of prepositions".
} 
and Chewa permit an independent pronominal to appear after $g \tilde{w i} / k w \tilde{w}$ and $k w a$, as illustrated in (20a-c) for Kikuyu and in (21a-c) for Chewa.

(20) Kikuyu
a. A-thi-ire kwĩ Mũthũngũ.
3S-go-PST to European
'He went to the European.'
b. A-thi-ire gwĩ $\tilde{u}$ ?
3S-go-PST to whom
'Whom did he go to?'
c. A-thi-ire gw-ake /gwĩ we.
3S-go-PST to.Asc.his (place) / to him
'He went to his home / to him.'

(21) Chewa

a. A-na-bwera kwa Joni.

3P-PST-come to John

'They came to John'

b. A-na-bwera kwa ndani?

3P-PST-come to who

'Whom did they come to?'
c. A-na-bwera *kw-ake / kwa iye
3p-TNS-come to-his (place) / to him

'They came to his place / to him' [Hullquist 1988:66]

In contrast to the marking by a preposition of destinations involving people, Swahili marks inanimates or general place names by a postposition. The suffix $-n i$, which denotes 'to, at, in', is illustrated in (22a). Proper place names do not carry the suffix, as illustrated in (22b).

(22) Swahili
a. A-na-kwenda nyumba-ni.
3S-PR-go house-to
'He is going home.'
b. A-na-kwenda Dar es Salaam /*-ni.
3S-PR-go Dar es Salaam
'He is going to Dar es Salaam.'

Like Swahili, Kikuyu uses a postposition, -ini 'at, near to, among, into', to mark certain locative relations [Mugane 1997:31, Barlow 1951:199]. Use of this 
form is illustrated in (23). Although "any noun" has the potential to become a locative [Mugane 1997:32], both common nouns and proper names may go unmarked for destination in Kikuyu, as shown in (24a-b).

Kikuyu

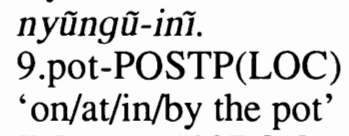

nyũngũ-inĩ.

9.pot-POSTP(LOC)

'on/at/in/by the pot'

[Mugane 1997:31]

(24) a. Twara ng' ombe rũũu.

take cattle river

'Take the cattle to the river.'

b. Tũ-gĩkinya Kĩnjabi.

1P-arrive Kijabe

'We arrived at Kijabe.' [Barlow 1951:198]

In Chewa, the locative $k u$ is used before both proper and common names. However, it is written separately from the proper name, as shown in (25a), and as an prefix for common nouns, as shown in (25b) [Orr and Myers-Scotton $1980: 86$, vol. 1].

(25) Chewa [Orr and Myers-Scotton 1980:227, Book 1]

a. A-ku-pita ku Lilongwe.

3S-PR-go to Lilongwe

'He's going to Lilongwe.'

b. Ti-kul-pita pansi ku-sukulu.

1P-PR-walk to-school

'We're walking to school.'

The marking of locatives denoting 'to, at, in' in Swahili, Kikuyu, and Chewa is summarized below.

Locative

Swahili

Kikuyu

Chewa with Person

-Verb-FV kwa $\mathrm{N}_{\text {[animate] }}$

-Verb-FV $g w \tilde{w} / k w \tilde{i} \mathrm{~N}_{\text {[animate] }}$

-Verb-FV kwa $\mathrm{N}_{\text {[animate] }}$ with Place

-Verb-FV N[place] $-n i$

-Verb-FV N[place] -ini

-Verb-FV ku-N [place]

In addition to prepositional and postpositional markers of locatives in these three languages, there are comparable phrasal expressions. These expressions 
are equivalent to the English phrases 'inside of', 'on top of', 'underneath', etc. Structurally these phrases consist of a noun (in Chewa, this is a derived noun which bears a prefix) plus the relational stem $-a$. The relational stem -a bears one of the class prefixes. In Swahili, it is the class 9 prefix $y$-. In Kikuyu, it is either the prefix $y$ - or $w$-, and in Chewa, it is one of the locative prefixes: $p$-, $k u-, m u-$. Examples (26)-(28) illustrate some of these phrasal locatives for Swahili, Kikuyu, and Chewa.

(26) Swahili [Erickson and Gustafsson 1989:138]

a. Wa-ko ndani ya nyumba.

3P-LOC inside 9.ASC house

'They are inside of the house.'

b. Acha mi-zigo mbele ya nyumba.

leave 4-load in front 9.ASC house

'Leave the loads in front of the house.'

(27) Kikuyu

a. Kwĩ ũũki thĩñ wa mwatũ. there honey inside of.ASC beehive 'Is there any honey inside the beehive?' [Barlow 1951:203]

b. A-thi-ire mbere ya nyũmba.

3P-go-PST in front 9.ASC house

'They went in front of the house'

(28) Chewa [Orr and Scotton 1980:224-6, Book 1]

a. Ma-buku anga ali pa-nsi pa tebulo.

PL-book my are 16-under 16.ASC table

'My books are under the table.'

b. Anawo ali pa-tsogolo pa ine.

children are 16-in front 16.ASC me

'Those children are in front of me.'

These same phrasal locatives govern the genitive case for pronominal NPs in Swahili and Kikuyu. These NPs may be either animate or inanimate, as shown in (29) and (30). In Chewa, however, only pronominals with inanimate referents occur in the genitive case, as shown by the example in (31).

(29) Swahili

Wa-ko mbele yake.

3P-LOC in front 9.ASC.its/his/her

'They are in front of it/him/her.' 
(30) Kikuyu

A-thi-ire mbere yake.

3P-go-PST in front 9.ASC.its/his/her

'They went in front of it/him/her.'

(31) Chewa

Ma-buku anga ali pa-nsi pake / pa iye.

6-book my are 16-under 16.ASC.its / under him/her

'My books are under it/him/her.'

In summarizing the data observed so far with respect to clausal relations in sections 2-4, we have seen that subject marking correlates with head-marking in Swahili, Kikuyu, and Chewa. Object relations are also head-marked in the case of applicative NPs. Non-applicative object NPs are morphologically unmarked in double-object constructions. ${ }^{8}$ Lexical object NPs in simple transitive clauses are often cross-referenced on the verb in Swahili if the NP referent is animate. This is generally not true for Kikuyu and Chewa. Alternative patterns exist for some head-marked patterns in which a third argument co-occurs with the independent morpheme, $k w a / k w \tilde{i} / g w \tilde{i} / k \tilde{u} r \tilde{i}$.

As for phrasal relations, the genitive marker is an inflected adposition that functions as both a dependent and head. In some Bantu languages (e.g., Tonga and Tswana), the genitive marker occurs as an affix on the dependent lexical NP; in other Bantu languages (Swahili, Kikuyu, Chewa), it occurs as a free morpheme. However, for pronominals, the genitive marker is an obligatory prefix on the possessive stem in Tswana, Swahili, Kikuyu, and Chewa.

Another phrasal relation, the locative, is marked by a preposition and/or postposition. Locatives denoting 'to' or 'towards' mark their destination with $k w a / k w \tilde{w} / k \tilde{r} r \tilde{i}$ if it is a person, while destinations which are places having proper names are either left unmarked, as in Swahili and Kikuyu, or appear after $k u$, as in Chewa. Common place names either bear a suffix (Swahili and Kikuyu), occur after $k u$ (Chewa), or go unmarked (Kikuyu). Pronominal locatives are marked identical to lexical nouns exept the possessive stem is used in all cases in Swahili and the independent forms for persons in Chewa and Kikuyu. Inanimates also take the possessive pronominal stem in Swahili, Kikuyu, and Chewa.

The strategies for marking grammatical relations in the Bantu languages examined here are dependent on three factors: 1) the type of dependency or the grammatical relation itself (subject, object, instrumental, etc.); 2) the NP type (lexical-common vs. proper nouns; interrogative; or pronoun); and 3) the animacy of the NP referent.

8 In lieu of overt morphological marking, word ordering and context serve to distinguish object NPs in Swahili, Kikuyu, and Chewa. 
In the next section I reconsider two relations-instrumental and locativewith respect to their potential for both head and non-head-marking.

\section{Complementary patterns}

The first complementary pattern of head and non-head-marking in Swahili is the instrumental relation. Examples in (32) and (33) illustrate, respectively, the head-marked and non-head-marked patterns for Swahili.

Swahili

(32) a. A-li-kat-i-a

kisu.

3S-PST-cut-APP-FV 7.knife

'I cut with a knife.'

b. A-li-kat-i-a nini?

3S-PST-cut-APP-FV what

'What did he cut with?'

c. A-li-ki-kat-i-a.

3S-PST-7-cut-APP-FV

'He cut with it.'

(33) a. A-li-kata kwa kisu.

1S-PST-cut with 7.knife

'I cut with a knife.'

b. A-li-kata kwa kitu gani?

3S-PST-cut with thing which

'What did he cut with?'

c. A-li-kat-a na-cho.

3S-PST-cut with-7

'He cut with it.'

This complementary pattern does not exist in Kikuyu. Interestingly, Kikuyu uses both markings such that the applicative and the free form co-occur, as shown in (34).

(34) Kikuyu

A-tin-ir-ie na kahiũ.

3S-cut -APP-PST with knife

'He cut with a knife'

Chewa, like Swahili, has both a head-marked and non-head-marked pattern, as illustrated in examples (35a) and (35b), respectively. It also has the doublemarked pattern like Kikuyu, as illustrated in (36). 
Chewa

(35) a. A-ku-dula ndi mpeni.

3S-PR-cut with knife

'He cut with a knife.'

b. A-ku-dul-ir-a mpeni.

3S-PR-cut-APP-FV knife

'He cut with a knife'

(36) A-ku-dul-ir-a ndi mpeni.

3S-PR-cut-APP-FV with knife

'He cut with a knife'

These patterns are summarized in the schemas below.

\section{Instrument}

Swahili

Kikuyu

Chewa
-Verb-APP-FV N [instr] -Verb-APP-TNS na $\mathrm{N}_{\text {[instr] }}$

$$
\text { -Verb-APP-FV (ndi) } \mathrm{N}_{\text {[instr] }}
$$

-Verb-FV kwa $\mathrm{N}_{\text {[instr] }}$

-Verb-FV ndi $\mathrm{N}_{\text {[instr] }}$

Another relation which allows both head and non-head-marking in Swahili is the locative denoting 'at' or 'in a place'. In the Swahili example in (37a), the locative is marked on the verb by an applicative suffix and by the locative suffix -ni on the dependent noun. In contrast to the head-marked locative in (37a), the same relation is marked by the uninflected morpheme katika 'in' in (37b).

(37) Swahili [Ngonyani 1995:2, fn4]
a. A-li-l-i-a
chakula ofisi-ni.
3S-PST-eat-APP-FV food office-LOC
'He ate in the office.'
b. A-li-kula chakula katika ofisi. 3S-PST-ate food in office
'He ate food in the office.'

The chart in Figure 1 summarizes the grammatical relations having complementary structures-head-marked and non-head-marked-in Swahili. It shows that Swahili has the potential to mark four relations-accusative, applied, instrumental, and locative - either on the head, i.e. the verb, or with a function word/ phrase. These four relatively elastic grammatical relations contrast with the subject and genitive relations, which are confined to one strategy: the subject is cross-referenced on the verb and the genitive is marked by a derived preposition. 
Figure 1. Grammatical relations in Swahili

Grammatical relation Head-marked Non-head-marked

\begin{tabular}{|l|ll|}
\hline Accusative (source) & $\mathrm{x}$ & $\mathrm{x}$ (animate) \\
\hline Applied & & \\
Goal/recipient (see Bentley [in press]) & $\mathrm{x}$ & $\mathrm{x}$ (animate) \\
Beneficiary & $\mathrm{x}$ & $\mathrm{x}$ (animate) \\
\hline Instrumental & $\mathrm{x}$ & $\mathrm{x}$ \\
\hline Locative & $\mathrm{x}$ & $\mathrm{x}$ \\
\hline
\end{tabular}

The potential of the various grammatical relations in Swahili to have more than one possible means of grammatical marking is represented in the schema in Figure 2 below. The two poles correspond to the restricted head-marked (subject) and non-head-marked (genitive, etc.) relations while the center corresponds to those relations (accusative, applied object, instrumental, and locative) having more than one possibility for marking. The head-marked and non-headmarked patterns offer competing options for encoding grammatical relations in Swahili. Some speakers of Swahili as a second language prefer the non-headmarked option for marking the instrumental case.

Figure 2. Marking potential of grammatical relations in Swahili

Head-marked

Nonhead-marked

Subject

Accusative (animate)

Genitive

Applied object

Phrasal locative

Instrumental

Locative

In the following pairs of sentences, the $[k w a+\mathrm{NP}]$ examples were preferred to the head-marked ones by Kenyan Swahili speakers, whereas both patterns were considered acceptable by my Zanzibari informants (first-speakers of Swahili). These alternations do not occur in Kikuyu or Chewa.

Swahili

a. Ni-ta-kwend-e-a basi.

1S-FUT-go-APP-FV bus

'I will go by bus.' $10 \quad$ [Zawawi 1971:141]

9 Some speakers find the non-head-marking acceptable only in the context of 'at someone's dwelling' and not in the directional sense of 'to someone'.

10 Some speakers interpret this variation to mean "go towards the bus". [A.S.A. Nchimbi, p.c.] 
b. Ni-ta-kwenda kwa basi.

1S-FUT-go by bus

'I will go by bus.'

(39)

a. Ni-li-kat-i-a kisu.

1S-PST-cut-APP-FV knife

'I cut with a knife.'

b. Ni-li-kata kwa kisu.

1S-PST-cut with knife

'I cut with a knife.'

(40) a. A-li-end-e-a njia ipi?

3S-PST-go-APP-FV way which

'By which way did he go?'

b. A-li-enda kwa njia ipi?

3S-PST-go by way which

'By which way did he go?'

These examples illustrate the variety of morphosyntactic marking available to speakers of Swahili. They also point to the fact that function words play a significant role in marking grammatical relations in Swahili.

\section{Conclusion}

Even though Nichols' head-/dependent-marking distinction is an insightful measure for classifying languages according to their tendency for using affixal morphology in marking select clausal and phrasal relations, the distinction necessarily precludes the compensating role of function words. Moreover, the place of inflected adpositions which govern case is left unresolved within this schema of head- and dependent-marking.

The data in this study have shown that the marking of grammatical relations in Swahili is not a straightforward split between head-marked clauses and dependent-marked phrases. Swahili has the potential to mark both clausal and phrasal relations on the verb. 11 Furthermore, animacy and NP type (lexical, interrogative, pronominal) affect the morphosyntax of grammatical relations in Swahili. For example, NPs with animate referents are marked distinctly from inanimates and pronominals primarily occur as bound forms.

The failure of Nichols' head-/dependent-marked distinction to include functional words ignores the significant role these words play in marking important relations in Swahili. Function words are subject to many of the same generaliza-

${ }^{11}$ Although not discussed in this paper, Swahili has the potential to mark relative clauses on the verb or on the independent morpheme, amba-. 
tions as case markers [Croft 1988:174, fn 6). In fact, some Swahili speakers prefer to mark instrumentals with a function word rather than an applicative suffix. Thus, Nichols' description of the marking of grammatical relations in Bantu languages from the basis of the occurrence of affixal morphology on the head or dependent member of a constituent is ultimately too constrained to provide a felicitous account of the marking of grammatical relations in Swahili.

\section{REFERENCES}

Adam, Hassan. 1993. Kiswahili Intermediate Course. Colgne: Omimee Intercultural Publisher.

Barlow, A. Ruffell. 1951. Studies in Kikuyu Grammar. Edinburgh: Wm. Blackwood \& Sons.

Bentley, Mayrene. In press. "Head-marking versus dependent-marking in Swahili, Kikuyu, and Chichewa." In P. Kotey (ed.), New Dimensions in African Linguistics and Languages: Trends in African Linguistics, Vol.3. Lawrenceville, NJ: Africa World Press.

Bentley, Mayrene. 1994. "The syntactic effects of animacy in Bantu Languages." Ph.D. Dissertation, Indiana University.

Blake, Barry. 1994. Case. Cambridge: Cambridge University Press.

Cole, Desmond. 1955. An Introduction to Tswana Grammar. Cape Town: Longmans, Green and Co.

Croft, William. 1988. "Agreement vs. case marking and direct objects." In M. Barlow and C. Ferguson (eds.), Agreement in Natural Language, pp. 159179. Stanford: CSLI.

Erickson, Helen and Marianne Gustafsson. 1989. Kiswahili Grammar Notes. Uppsala: Church of Sweden Mission.

Hullquist, C. G. 1988. Simply Chichewa. Makwasa, Malawi: Malamulo Publishing House. 
Kanerva, Jonni. 1990. Focus and phrasing in Chichewa phonology. New York: Garland Publications, TNC.

Mugane, John. 1998. "Gikuyu NP morphosyntax." In I. Maddieson and T. Hinnebusch (eds.), Language History and Linguistic Description in Africa, Vol. 2, pp. 239-248. Trenton, NJ: Africa World Press.

Mugane, John. 1997. A Paradigmatic Grammar of Gikuyu. Standford: CSLI Publications.

Ngonyani, Deo. 1995. "Towards a Typology of Applicatives in Bantu." Paper presented at the 26th Annual Conference on African Linguistics at the University of Los Angeles.

Nichols, Johanna. 1986. "Head-marking and dependent-marking grammar." Language 62: 56-119.

Orr, Gregory John and Carol Meyers-Scotton. 1980. Learning Chichewa, Books 1 and 2. Michigan State University: African Studies Center.

Vitale, Anthony. 1981. Swahili Syntax. Dordrecht: Foris Publications.

Zawawi, Sharifa. 1971. Kiswahili kwa Kitendo. New York: Harper \& Row.

Department of Linguistics and Languages

Michigan State University

East Lansing, MI 48824

bentle16@pilot.msu.edu
[Received October 1997; revision received May 1998; accepted September 1998] 
